\title{
Research on the Elements of Green Consumption Situation
}

\author{
Qiyao Zhang1, a, Xixiang Sun ${ }^{1, b}$ and Linghui Cai ${ }^{2, c}$ \\ ${ }^{1}$ School of Management, Wuhan University of Technology, Wuhan 430070, China; \\ ${ }^{2}$ School of Economics, Zhongnan University of Economics and Law, Wuhan 430073, China. \\ aimutzqy@163.com, bsunxx-102@163.com, cclh2013023@163.com
}

\begin{abstract}
Besides consumers' personal factors, situations are also important in green consumption process. Through the background research on the conception and the construction of situation, the analysis method on the green consumption situation is determined. Based on the PEST model, the elements of green consumption situation are generalized and summarized. There are four elements are presented: policy situation; economic situation; technology situation and sociocultural situation. The study on the elements of green consumption situation can improve the enterprises to understand the external cues for green marketing more clear.
\end{abstract}

Keywords: Green consumption, Situation, PEST model.

\section{Introduction}

The sustainability and green life-styles are rising gradually with the ecological deterioration and the improvement of residents' eco-awareness. Green consumption has become an important way for the people to take part in the program of environmental protection. The true level of green consumption is very low in the real world. There is a big gap between the consumers' attitude and behavior for the green consumption. The consumers' personal factors such as low environment protection awareness have been cited as the explanation for the gap. But it cannot be ignored that the green consumption situations have an equally impact on the green consumption attitude and behavior. Situation as a kind of external stimulation will have a direct effect on the consumer behavior. Besides that, according to the trait activation theory, the perception of the situation for the individual can adjust the relationship between the individual characteristic and behavior. Based on the action strength of the situation on the individual behavior, the situation can be divided to two parts: strong situation and weak situation. The differences of individuals will be lower and the consistencies will be higher in the strong situation. And the expressions of individuals in the weak situation are just the opposite. Thus it can be seen that situation not only affects the individual behavior, but also adjusts the relationship between the individual characteristic and behavior. Grimmer et al. [1] have research the effect of green consumption situation to the green consumption behavior, and have presented the measurement scale of green consumption situation. But the study did not generalize and summarize the elements of green consumption situation. There is lack of theoretical researches on the construction of the green consumption situation now. The research on the elements of situation can provide a second parallel approach to study the consumers' green consumption behaviors.

The aim of this study is to propose the main elements of the green consumption situation based on the situation theory and available literatures of green consumption. And the effect of each element of green consumption situations on the green consumption behavior will be explained. The conclusions can promote the enterprises to design reasonable green consumption situations and stimulate the consumers' green consumption desire.

\section{Literature References}

There are two ways to definite the conception of situation. The first one is based on the view of objective existing. The objective existing situation regards the situations are the observed facts which affect the individual behavior systematically and provability at a given time and place. And these facts don't come from the individual understanding for the situations. The second one is based on the view 
of subjective existing. The subjective existing situation regards the situations are the individual internal response for the observed facts which affect the individual behavior systematically and provability at a given time and place. And the subjective existing situation is a temporary state which is completely independent from the individual and object. No matter how different of the two conceptions, the situations are formed by the observed facts at a given time and place. The situation will have an effect on the individual characteristic and behavior.

The Belk's classification about consumption situations is the most widely used in the researches. The situations are consisted of physical surroundings, social surroundings, time, task definition and antecedent states [2]. There are major facts constitute the consumption situations. All elements of the consumption situations cannot be listed out. The key elements of the consumption situations which play an important part in green consumption will be summarized. Jingqin Su and Linlin Zhang [3] learned from the PEST model and a method with micro and macro analyses was proposed for classifying the situations. This method includes not only objective situations, but also conceptive situations. The objective situations are composed by the economics, policies, technologies and products. And the conceptive situations are composed by the social cultures, customs and habits. This article employs this method which should more comprehensive cover factors of the situations for the research.

\section{Elements of Green Consumption Situation}

\subsection{Policy Situation.}

The policy situation can be the big factor affecting the green consumption. There are important challenges for the economic and social sustainable development in China. For the people's health, Chinese government has promulgated some important laws about the green development. Firstly, the policy situation can promote the enterprises to achieve green technologies innovation and produce more green products for the market. The enterprises can raise their green produces market percentage and the brand influence. There is also opportunity for consumers to be able to interact with the green products and green brands. Secondly, the policy situation can provide an open atmosphere that boosts consumers' green consumption enthusiasm. The consumers' green consumption behavior can be optimized through specification and control of green consumption decision-making process by the policy situation. Being the center of the social sources, the government's laws about the green development will promote the green consumption level of the whole society and have a strong green consumption demonstration effect. Also, the policy situation can form new social norm for the green consumption. The social norm pressure will enhance the initiative of the green consumption.

\subsection{Economic Situation.}

The economic situation represents the economic development and the people's income. The high economic development means the enterprise can put more source and money for the green innovation and green product. And the market of green products will be further expanded. The green features of green products and brands can be identified by consumers more easily. And the perceived quality of the green products and brands can stimulate the appetites and demands of the green consumers. The price of the green products is higher than the normal products. The consumers need pay more for the green products. The rise of people's income is the economic foundation of the increasing green products and green consumption. The consumers can afford the price of the green products by the rise of the income. And the consumers can choose and purchase the green products more freedom. Thus it can be seen that economic situation has a more direct effect on the green consumption.

\subsection{Technology Situation.}

There is no uniform standard for the green technology and green product. Some consumers cannot identify the green products in the market. But the high price of the green products has received most attention by the poor enterprise. They obtain sudden huge profits through green washing which produce the sharpest drop in consumer confidence for the green products [4]. The green washing seriously disturbs the green consumption market rule. The distrust for the green products and brands 
is spreading in the green consumers. The fine technology situation is an important foundation for the consumer confidence of green products. The government should guide enterprises to establish a uniform industry standard for the green technology and green products. And it is great importance to strengthen the intellectual property protection on the green technology and green products. This will not only safeguard the legal rights and interests of green enterprises, but also strengthen the awareness of consumers on green consumption. The unique differences between the green technology and normal technology can improve the consumers' trust for the green products and brands.

\subsection{Sociocultural Situation.}

The sociocultural situation is based on the social value and culture value. Chinese culture is profound, which contains a lot of unique culture. These social cultures have a non-negligible impact on the people thinking. For example, Confucian thoughts on ecological ethics play an important inspirable role in the chase for sustainable development. It follows that there are subconscious of environmental protection in the Chinese. The subconscious need some mechanisms and measures to wake it up. By enhancing the traditional local culture identity, the people's social environmental awareness will be strengthened. The average propensity to green consumption can be improved. Also, the Chinese people agree that face-saving is important. They are susceptible to other's comments and behaviors. In order to gain social recognition, they will remain consist with the reference groups [5]. It is very important to give play to the role of influence of the reference groups on the green consumers. The establishment of the sociocultural for environmental protection and altruistic involves the government's involvement, as well as the all citizens' participation. The institution ethics restraint can enhance the consumer's self constraint for the bad consumption habits and form a healthy public environment for the green consumption.

\section{Summary}

To develop the green consumption depends upon appreciating how situation is built. The consumers' behaviors are normally influenced by the various portfolio elements of green consumption situation. Different elements of green consumption situation can achieve different results on the green consumption. With the study of PEST model, the four elements of green consumption situation are put forward: policy situation; economic situation; technology situation and sociocultural situation. Only based on the consumers' personal factors and elements of green consumption situation, the enterprises can solve the problems of green consumption in a reasonable and high-efficient way.

\section{References}

[1] Grimmer, Martin, Ashley P. Kilburn, Morgan P. Miles. The Effect of Purchase Situation on Realized Pro-environmental Consumer Behavior. Journal of Business Research. Vol. 69 (2016) No. 5, p. 1582-1586.

[2] Belk, Russell W. Situational Variables and Consumer Behavior. Journal of Consumer Research. Vol. 2 (1975) No.3, p. 157-164.

[3] Jingqin, Su, and Linlin, Zhang. Context Concept,Classification and Current Situation of Contextualization. Chinese Journal of Management. Vol. 13 (2016) No.4, p. 491-497.

[4] Delmas, Magali A., and V. C. Burbano. The Drivers of Greenwashing. Social Science Electronic Publishing. Vol. 54 (2011) No.1, p. 64-87.

[5] Aizhong, He, Tianxiang, Deng. A Study of Formation Mechanism of Typical Nongreen Consumption Behavior. Economic Management Journal. Vol. 36 (2014) No.1, p. 77-87. 